\title{
REFORMASI HUKUM PERPAJAKAN DALAM UPAYA MENINGKATKAN PENERIMAAN DAN KEPATUHAN WAJIB PAJAK
}

\author{
Djoko Santosa \\ Program Studi Magister Ilmu Hukum, Fakultas Hukum, Universitas Narotama \\ e-mail: santosadjoko@ymail.com \\ Rusdianto Sesung \\ Fakultas Hukum, Universitas Narotama \\ e-mail: rusdianto@narotama.ac.id
}

\begin{abstract}
ABSTRAK
Reformasi hukum perpajakan di Indonesia baik dalam arti perubahan atau perbaikan merupakan kewajiban Pemerintah secara dinamis dan terus-menerus. Reformasi perpajakan ini dilatarbelakangi oleh kebutuhan mengurangi kesenjangan antara peningkatan penerimaan negara dan kepatuhan wajib pajak. Reformasi aturan perpajakan yang tegas, adil dan proporsional merupakan urgensi dalam penegakan pajak ke arah yang lebih responsif dan antisipatif, namun tetap harus sesuai dengan situasi politik hukum pada masanya. Reformasi hukum pajak ke arah reformasi birokrasi dan reformasi lima pilar utama yakni Organisasi, SDM, IT dan Basis Data, Proses Bisnis, dan Peraturan Perpajakan sehingga terjadi peralihan penekanan politik hukum reformasi perpajakan dimana pajak sebagai alat stimulus kepatuhan para wajib pajak bukan hanya sekedar meningkatkan penerimaan pajak secara materiil. Penelitian hukum normatif dengan pendekatan perundang-undangan dan pendekatan konseptual ini membahas mengenai reformasi aturan perpajakan yang semakin mengarah pada penyederhanaan perpajakan secara final tapi tetap memperhitungkan faktor praktek perpindahan sistem perpajakan dari global ke schedule tax system. Penelitian ini mensarankan agar simplifikasi perpajakan diterapkan melalui aspek kebijakan, prosedur, administrasi, dan tata cara komunikasi antara wajib pajak dan fiskus, semuanya mengarah pada peningkatan kepatuhan, kontinuitas pemasukan negara, kemudahan partisipasi wajib pajak, peningkatan kemampuan bersaing, pengumpulan basis data wajib pajak dan kemudahan penerapan regulasi pajak.

Kata Kunci: reformasi hukum pajak; politik hukum; penyederhanaan pajak
\end{abstract}

\section{ABSTRACT}

Tax reform in Indonesia, either in the sense of amendment or restoration, is a dynamic and continuous obligation of the Government. This tax reform was motivated by the need to reduce the gap between increasing state revenue and taxpayer compliance. Tax law reform that are firm, fair and proportional is an urgency in tax enforcement to be more responsive and anticipatory, but still must be in accordance with the political and legal situation of its time. Tax reform towards bureaucratic reform and reform of the five main pillars, namely Organization, Human Resources, IT and Databases, Business Processes, and Tax Regulations so there is a shift in the political emphasis of tax reform law where taxes are a means of stimulus for taxpayer compliance, not just increasing revenue. tax materially. This normative legal research with a statutory approach and a conceptual approach discusses the reform of taxation rules that increasingly leads to final simplification of taxation but still takes into account the practice of moving the tax system from the global to the tax system schedule. This research recommends that the implementation of tax simplification through aspects of policies, procedures, administration, and communication procedures between taxpayers and tax authorities must lead to increased compliance, continuity of state revenue, ease of taxpayer participation, increased competitiveness, collection of taxpayer databases and ease of tax regulations implementation.

Keywords: tax reform; politics of law; tax simplification 


\section{PENDAHULUAN}

Peningkatan target penerimaan pajak setiap tahun hingga kini belum diimbangi dengan kenaikan kepatuhan wajib pajak sehingga terjadi kondisi yang tidak sebanding. Wajib pajak umumnya masih menghindari pembayaran pajak selama tidak ada pengawasan dan penagihan, bahkan tagihan pajak menjadi hal yang seolah membebani dan dapat dihindari (tax evasion). Cerminan kondisi perpajakan negara dapat dibaca dari rasio pajak (tax ratio) yang jeblok di angka $10 \%$ jauh dari syarat standar rasio pajak untuk pembangunan nasional yaitu $15 \% .{ }^{1}$

Penanganan pajak selayaknya adil (proposional), ${ }^{2}$ serta diimbangi dengan aturan perundangan dan penerapan yang serasi. ${ }^{3}$ Ada keseimbangan antara sisi kepastian, keadilan, dan kemanfaatannya agar dapat menjadi pedoman dan arahan bagi Wajib Pajak (selanjutnya disebut WP) dan fiskus dalam melaksanakan hak dan kewajibannya.

Kebutuhan reformasi aturan hukum perpajakan diperlukan bukan saja sebagai aturan yang bersifat responsif tapi juga antisipatif dalam mengatasi masalah perpajakan di masa depan karena kekuasaan (politik) yang tidak diimbangi oleh kepastian hukum akan menjadi arogansi yang sia-sia, begitu pula aturan pajak memperhatikan situasi politik hukum terkini agar tidak sekedar menjadi alat propaganda politik. ${ }^{4}$ Kondisi aturan hukum di bidang perpajakan yang masih berbenturan satu sama lain dapat menciderai rasa keadilan dan merugikan Wajib Pajak.

Oleh sebab itu, perlu adanya pemahaman dan pemikiran terhadap simplikasi penerapan pajak khususnya pajak penghasilan (selanjutnya disebut $\mathrm{PPh}$ ) terhadap WP Orang Pribadi (WP OP) sebagai pedagang dan industri yang bersifat final, berbeda dengan $\mathrm{PPh}$ pekerja bebas maupun pegawai dengan $\mathrm{PPh}$ bertarif umum, khususnya yang penghasilan dari usaha tidak melebihi 4,8 milyar. Hal ini dikuatirkan dapat melanggar prinsip kesetaraan di depan hukum

${ }^{1}$ Darussalam, et.al. (2019). Era Baru Hubungan Otoritas Pajak dengan Wajib Pajak. Jakarta: PT. Dimensi Internasional Tax, h. 2 .

${ }^{2}$ Hyronimus Rhiti. (2015). Filsafat Hukum Edisi Lengkap (Dari Klasik ke Postmodernisme). Cetakan Kelima. Yogyakarta: Universitas Atma Jaya, h. 241.

${ }^{3}$ Mardiasmo, (2016). Perpajakan Edisi Revisi. Yogyakarta: Andi Offset, h. 2

${ }^{4}$ Mahfud. (2010). Politik Hukum. Jakarta: PT. Raja Grafindo Persada, h. 1. dimana setiap Wajib Pajak berhak untuk diperlakukan secara adil dan setara dalam mendapatkan layanan di bidang perpajakan.

Penelitian terdahulu mengenai reformasi perpajakan pada umumnya dan pajak penghasilan pada khususnya diantaranya yakni penelitian oleh Deden Sumantry di tahun 2011 mengenai reformasi pajak yang berfokus pada perlindungan hukum WP dengan petugas DJP yang merupakan pelaku dalam UU Perpajakan. ${ }^{5}$ Selanjutnya penelitian oleh Hillary S.P. Ratuela, Jullie J. Sondakh, dan Anneke Wangkar di tahun 2018 yang lebih berfokus pada penerapan PPh Final Pasal 4 (angka 2) atas jasa yang berkaitan dengan konstruksi. ${ }^{6}$ Penelitian oleh Cinantya Kumaratih dan Budi Ispriyarso di tahun 2020 yang lebih menekankan kebijakan penurunan tarif $\mathrm{PPh}$ final bagi UMKM. ${ }^{7}$ Penelitian kali ini berbeda karena lebih menekankan pada sudut pandang politik hukum yang melatarbelakangi reformasi hukum pajak dengan menitikberatkan pada simplifikasi perpajakan.

\section{PERUMUSAN MASALAH}

Rumusan masalah yang diidentifikasikan dalam penelitian ini adalah apakah politik hukum reformasi peraturan perpajakan yang melatarbelakangi reformasi hukum perpajakan dan simplifikasi perpajakan dalam meningkatkan kepatuhan Wajib Pajak.

\section{METODE PENELITIAN}

Penelitian hukum normatif dengan penelaahan kepustakaan ini menggunakan pendekatan perundang-undangan (statute approach) serta pendekatan konseptual (conceptual approach).

5 Deden Sumantry. (2011). "Reformasi Pajak untuk Perlindungan Hukum di Antara Wajib Pajak dengan Fiskus Sebagai Pelaksanaan Terhadap UU Perpajakan". Jurnal Legislasi Indonesia. Vol. 8 No. 1 April 2011, h. 13-28.

${ }^{6}$ Hillary S.P Ratuela, Jullie J. Sondakh, Anneke Wangkar. "Analisis Penerapan Pajak Penghasilan Final Pasal 4 Ayat 2 Atas Jasa Konstruksi Pada PT. Realita Timur Perkasa”. Jurnal Riset Akuntansi Going Concern. 13(4), 2018, h. 856-866.

${ }^{7}$ Cinantya Kumaratih dan Budi Ispriyarso. "Pengaruh Kebijakan Perubahan Tarif PPH Final Terhadap Kepatuhan Wajib Pajak Pelaku UMKM". Jurnal Pembangunan Hukum Indonesia. Vol. 2 No. 2 May 2020, h. 158-173. https://doi. org/10.14710/jphi.v2i2.158-173 


\section{PEMBAHASAN}

Reformasi perpajakan ditinjau dari reformasi aturan perundang-undangan di bidang perpajakan dan reformasi birokrasi perpajakan. Kedua aspek tersebut saling berkaitan satu sama lain. Pembahasan akan dibagi sesuai periode waktu.

\section{Reformasi Undang-Undang Perpajakan}

Reformasi perpajakan ini diawali tahun 1983 yang terbagi dalam beberap tahap yakni fase reformasi UU PPh tahun 1983,

\section{a. Reformasi UU PPh Tahun 1983}

Tahun 1983 merupakan tahun terjadinya reformasi pajak pertama kali secara modern, UU PPh tersebut sebenarnya merupakan kompilasi dari beberapa berbagai macam pajak sebelum tahun tersebut, yakni ordonansi/aturan pajak pendapatan (penghasilan) 1944 (PPd), ordonansi/aturan pajak perseroan (badan) 1925 (PPs), UU perihal pajak atas hasil bunga, dividen dari perusahaan dan royalti 1970 (PDBR), serta UU bernomor 8 Tahun 1967 juncto PP bernomor 11 Tahun 1967, yang berkaitan dengan perlakuan pajak terhadap penghasilan. Tujuannya untuk penyederhanaan (simplikasi), kemudahan dan kepatuhan.

Penghasilannya tidak tergantung pada keberadaan dan pembatasan sumbernya, dan secara total semua penghasilan dihitung pajaknya (global taxation system $),{ }^{8}$ tapi terkhusus hasil bunganya deposito yang terdapat jangka waktunya dan simpanan lainnya dihitung terpisah yang merupakan pemasukan dana pembangunan (PPh final).

Pada tahun 1983 ke bawah, Kantor Inspeksi Pajak (tahun 1983 berubah nama jadi Kantor Pelayanan Pajak) melakukan perhitungan dan menetapkan pajak yang terutang oleh Wajib Pajak (WP). Politik hukum dalam rangka peningkatan jumlah WP dan bentuk pendeklarasian diri sebagai bangsa, berdikari, berdaulat dan merdeka, maka mulai tahun 1983 diberlakuan sistem self assessment. Ada penurunan lapisan tarif $\mathrm{PPh}$ dari $45 \%$ menjadi $35 \%$ serta penyederhanaan struktur tarifnya baik WP OP maupun WP Badan.

Reformasi pajak 1983 ini cukup sukses dalam mendongkrak penerimaan pajak, tapi peran sumber

\footnotetext{
${ }^{8}$ Lee Burns dan Richard Krever. "Individual Income Tax" dalam Tax Law Design and Drafting. Volume 2 ed. Victor Thuronyi (United Kingdom: IMF, 1998), h. 495.
}

daya manusia dalam negeri sebagai konsultan belum banyak terlibat.

Penyebutan PPh final Tahun 1983 belum banyak diperkenalkan, penyebutan biasanya berkaitan dengan PPh yang berpasal 21 untuk karyawan dan PPh yang berpasal 26 atas penghasilan SPLN (Subyek Pajak Luar Negeri). Pajak dari penghasilan karyawan yang diperoleh dari pemberi kerja, hal ini diatur dalam Pasal 21 ayat (1), ayat (2), ayat (5) dan ayat (7), serta Penjelasan Pasal 21 ayat (7) UU PPh. Ringkasan ayat-ayat pasal 21 bahwa WPDN yang dapat hasil semata-mata dari pekerjaan, maka pajak yang telah dipotong atas dinyatakan final, tidak lagi diwajibkan menyampaikan SPT tahunan.

Pasal 26 UU PPh, mengandung aturan perihal pemotongan pajak bagi SPLN, yang pokok-pokok bahasannya adalah: 1. Jumlah bruto pembayaran sebagai Dasar Pengenaan Pajak(DPP), 2. Tarif pajak sebesar 20\% dari DPP dan bersifat final. Objeknya, penghasilan pasif, yaitu bunga, dividen, royalti, sewa, dan sebagainya.

Penyebutan pajak final juga terdapat di Penjelasan Pasal 8 ayat (1) yang mengandung langkah teknis penggabungan penghasilan atau kerugian istri ke dalam penghasilan atau kerugian suaminya. Pemotongan PPh 21 dari Penghasilan isteri bersifat final, bila penghasilan tidak berhubungan dengan usaha suami. ${ }^{9}$ Pengenaan pajak final $\mathrm{PPh}$ yang berpasal 4 (angka 2) mulanya berkaitan dengan hasil dari bunganya deposito ada jangka waktunya dan simpanan lainnya. Pelaksanaan pasal ini dibuatkan Peraturan Pemerintah (PP) No. 37 Tahun 1983 (PP 37/1983) perihal pengenaan $\mathrm{PPh}$ dari hasil bunganya deposito yang ada jangka waktunya dan simpanan bentuk lainnya yang dipunyai warga RI, yang pelaksanaannya ditunda pemerintah hingga masa yang diatur selanjutnya.

Tiga tahun kemudian terbit PP No. 13 Tahun 1988 yang mengatur $\mathrm{PPh}$ dari hasil bunganya deposito yang ada jangka atau masanya, deposito yang berwarkat/bersertifikat dan simpanan yang mengatur perihal hasil bunganya deposito yang ada jangka atau masanya, deposito berwarkat/ bersertifikat dan simpanan dipunyai WP OP dan WP Badan dibebani $\mathrm{PPh}$ dengan tarif $15 \%$ dan berkriteria final.

\footnotetext{
${ }^{9}$ Untuk lebih jelasnya, dapat dilihat pada ilustrasi contoh dalam Penjelasan Pasal 8 ayat (1) UU No. 7 Tahun 1983.
} 
Satu tahun berikutnya, terbit pengaturan pajak final atas hasil bunganya deposito ada jangka temponya dan simpanan dalam PP No. 21 Tahun 1989 (PP 21/1989) jo. PP Nomor 54 Tahun 1990 (PP 54/1990) perihal $\mathrm{PPh}$ atas hasil bunganya deposito yang ada temponya, deposito yang berwarkat/ bersertifikat dan simpanan yang tetap menerapkan $\mathrm{PPh}$ final sebesar $15 \%$ dari hasil bunganya deposito yang terdapat jangka waktunya, deposito yang berwarkat/bersertifikat dan simpanan.

Perihal Pasal 15 UU PPh Tahun 1983, diatur tentang norma penghitungan khusus untuk hitung hasil bersih WP yang dikhususkan dan tak bisa dilakukan penerapan Pasal 16 UU PPh (mekanisme umum), tapi definisi wajib pajak tertentu belum ada.

Sedang Pasal 22 UU PPh belum ada isu bersifat final, pasal ini sebenarnya memuat aturan sebagai berikut: 1. Perusahaan/WP Badan yang dikhususkan untuk melakukan tugas pungut pajak WP yang bergerak di usaha/bisnis impor; atau 2. Aktivitas bisnis sektor lainnya yang mendapat bayaran atas barang dan jasa dari belanja negara.

\section{b. Reformasi UU PPh Tahun 1991}

Pengaturan $\mathrm{PPh}$ final dari tahun 1983 tidak banyak diubah dalam perombakan pertama UU PPh ini, tapi pemerintah menerbitkan aturan pelaksana Pasal 4 ayat (2) terbaru yaitu aturan PP 74/1991 mengenai PPh dari hasil bunganya deposito yang terdapat jangka waktunya, warkat SBI, deposito yang berwarkat/bersertifikat dan simpanan. Ada perubahan yang berarti tentang beda tarif antara bunga dari deposito yang ada jangka waktunya, deposito yang berwarkat dan simpanan serta rabat warkat SBI yang diterima WP OP tarifnya $15 \%$ final, WP Badan tarif Pasal 17 tidak final dan WP LN tarif $20 \%$ final (dengan mempertimbangkan tarif dalam tax treaty /P3B).

Pengklasifikasian yang berbeda terhadap sumber penghasilan, tak membuat adanya penerapan terpisah atas pajak dengan perhitungan tarif umum UU PPh (ring-fencing), sedang bila menelaah Pasal $26 \mathrm{UU} \mathrm{PPh}$ yang bersifat final terhadap penghasilan (terutama modal) dari SPLN (tidak kewajiban lapor SPT), maksudnya untuk kemudahan saja. ${ }^{10}$ Penghasilan dari

\footnotetext{
${ }^{10}$ Richard M. Bird dan Eric M. Zolt. "Dual Income Taxation and Developing Countries". Columbia Journal of Tax Law. Vol. 1 (2010): 201.
}

modal yang diterima SPDN, perlakuannya dengan withholding tax $\mathrm{PPh}$ yang berpasal 23 dan merupakan kredit/pengurang terhadap pajak yang dihitung secara tarif umum. ${ }^{1112}$

\section{c. Reformasi UU PPh Tahun 1994}

Dalam amandemen UU PPh Tahun 1994 diatur klasifikasi perhitungan tarif pajak dari penghasilan bersifat final. ${ }^{13}$ Hal ini mengindifikasikan sudah ada perpindahan dari global tax system ke schedular tax system. ${ }^{14}$ Beberapa contoh penerapan $\mathrm{PPh}$ Final dalam UU ini misalnya PPh bunga dari bank (deposito dan tabungan) tarif 20\%. Lalu penerapan $\mathrm{PPh}$ final atas jual tanah dan/atau bangunan, bertarif 5\% dari nilai penjualan/pelepasan objek pajaknya. $\mathrm{PPh}$ berkriteria final juga berlaku pada pelepasan saham di pasar saham RI (BEI) dan bertarif $0,1 \%$ dari harga jual saham.

Politik hukum dari reformasi pajak tahun 1994 dapat diringkas berupa tujuan untuk memastikan apa yang digariskan ketika perombakan UU perpajakan di tahun1983, yakni: a. Simplikasi, pelaksanaan jelas dan mudah baik bagi WP maupun fiskus; $b$. Prinsip penerapan yang dan proporsional atas pajak yang terbebankan; c. Ada ketentuan pasti/baku dalam hukum baik untuk WP maupun fiskus; $d$. Meminimalisir celah tax evasion; e. Perhitungan pajak sesuai kewajiban WP; f. Faktor stimulasi untuk pembangunan.

Faktor globalisasi dan persaingan untuk menggaet para pelaku investasi dari dalam dan luar negeri antar negara-negara asia tenggara, diantisipasi sebagai bagian politik hukum reformasi pajak tahun 1994 dengan memberlakukan tarif pajak yang bersaing.

Ada empat UU yang alami perubahan dalam reformasi pajak tahun 1994, sebagai berikut:

Pertama, UU bernomor 9 bertahun 1994 merupakan perubahan atas UU No. 6 Tahun 1983

${ }^{11}$ Michael Carnahan. "Taxation Challenges in Developing Countries”. Asia \& Pacific Policy Studies. Vol. 2 No. 1 (2015): 176.

12 Christian Vossler dan Michael McKee. "Behavioral Effects of Tax Withholding on Tax Compliance: Implications for Information Initiatives". Department of Economics Working Paper. No. 15-12 (2015): 1.

${ }^{13}$ Penjelasan Pasal 4 ayat (1) UU PPh Tahun 1994.

14 Sylvan R.F. Plasschaert. (1988). Schedular, Global and Dualistic Patterns of Income Taxation. Amsterdam: IBFD, h. 17. 
tentang KUP (Ketentuan Umum dan Tata Cara Perpajakan).

Kedua, UU bernomor 10 bertahun 1994 merupakan UU PPh, perombakan atas UU bernomor 7 bertahun 1983 yang telah dirombak sebelumnya dalam UU No. 7 Tahun 1991.

Ketiga, UU bernomor 11 bertahun 1994 merupakan perubahan atas UU No. 8 Tahun 1983 perihal PPN yang mengatur perpajakan atas tambahan ekonomis barang dan jasa dan PPnBM yang merupakan perpajakan terhadap pelepasan benda kategori mewah/eksklusif.

Keempat, UU No. 12 Tahun 1994 merupakan perombakan atas UU bernomor 12 bertahun 1985 perihal PBB yang perpajakan atas tanah dan unit yang dibangun di atasnya.

Tarif progresif $\mathrm{PPh}$ turun 35\% menjadi 30\%. Jangka daluwarsanya berubah dari lima tahun jadi sepuluh tahun. Arah politik hukum dari reformasi 1994 ini bisa tercapai bila didukung dengan upaya berikut ini: a. Partisipasi banyak WP; b. Simplifikasi aturan pajak dan perhitungan; c. Pengurangan celah kecurangan perpajak; d. Pajak tidak digunakan sebagai alat kampanye para polikus. ${ }^{15}$

Reformasi pajak tahun 1994 juga memberi peluang perombakan yang besar pada aturan $\mathrm{PPh}$ final di Indonesia. ${ }^{16}$ Beberapa aturan yang diubah, yaitu:

1. Penambahan macam obyek hasil/pendapatan yang ditarik pajak kategori final Pasal 4 (angka 2).

Penambahan ini meliputi sehingga menjadi diantaranya berasal: (1) hasil bunganya deposito dan simpanan lainnya, (2) pelepasan saham/ efek dan sekuritas lainnya di pasar saham/efek Indonesia, (3) pelepasan harta berupa tanah dan/ atau sesuatu yang dibangun di atasnya, serta (4) pendapatan terkhusus lainnya, yang tata caranya terdapat dalam aturan dari Pemerintah (PP), ${ }^{17}$ dalam perubahan pasal ini ada penambahan $\mathrm{PPh}$ final Pasal 4 (angka 2) sehingga berubah jadi

15 Carl Joachim Friedrich. (2004). Filsafat Hukum Perspektif Historis. Bandung: Nuansa dan Nusamedia, h. 239.

${ }^{16}$ B. Bawono Kristiaji dan Awwaliatul Mukarromah. Meninjau Konsep dan Relevansi PPh Final di Indonesia. DDTC Working Paper 2220. Tgl. 04 Mei 2020, h. 32.

${ }^{17}$ Pengenaan pajak yang bersifat final baru disebutkan pada berbagai Peraturan Pemerintah turunan dari Pasal 4 ayat (2) UU PPh Tahun 1994.
3 (tiga) macam objek pajak juga terdapat frase kata 'penghasilan tertentu lainnya' yang memberi peluang pengenaan pajak final bagi penghasilan lain oleh DJP (pemerintah), tapi istilah pajak final kurang diperjelas.

Pada penjelasan Pasal 4 (angka 2) pembebanan pajak bersifat final sebagai semangat kemudahan administrasi dalam penerapannya, sehingga simpanan WP yang masuk ke perbankan dan bursa efek sebagai sumber pemasukan untuk pembangunan, pajaknya mendapat perlakuan tersendiri (simplifikasi).

Penerbitan PP yang atur cara pengenaan pajak final gencar pada reformasi ini. Ada aturan pembaharuan berupa PP 51 tahun 1991 (PP 51/1991) yang mengatur perihal $\mathrm{PPh}$ terhadap hasil bunganya deposito, simpanan, dan rabat warkat SBI, berlanjut dengan diubah PP bernomor 41 bertahun 1994 (PP 41/1994) menjadi PP bernomor 14 bertahun 1997 (PP 14/1997) mengenai $\mathrm{PPh}$ terhadap pelepasan saham/efek di pasar saham/efek. Peraturan Pemerintah terkait pengalihan tanah dan/atau bangunan alami perubahan beruntun dari PP No. 3/1994, PP bernomor 48 bertahun 1994, PP bernomor 27 bertahun 1996, dan PP bernomor 79 bertahun 1999 .

Penghasilan tertentu lainnya yang dibebani PPh final berpasal 4 (angka 2) diatur dalam PP yakni: (a) PP No. 42/1994 mengatur pajak final hadiah undian; (b) PP No. 46/1996 perihal PPh dari hasil bunganya atau rabat obligasi yang ditransaksikan di pasar saham/efek; (c) PP No. 29/1996 perihal persewaan bumi dan/atau yang dibangun di atasnya; (d) PP No. 73 Tahun 1996 tentang jasa konstruksi; dan (e) PP No. 4/1995 mengatur $\mathrm{PPh}$ terhadap pendapatan permodalan patungan dari pelepasan saham/efek maupun pengikut-sertaan permodalan. ${ }^{18}$

Perlakuan tersendiri pada penghasilan dari modal semakin diperjelas melalui PP tersebut di atas, baik itu dari persewaan tanah, pelepasan kepemilikan terhadap tanah dan/atau termasuk sesuatu yang dibangun di atasnya, dan

${ }^{18}$ Lihat PP No. 42 Tahun 1994. 
sebagainya, tidak luput juga terhadap hadiah undian. ${ }^{19}$

Ini indikasi ada kelemahan dalam pengaplikasian comprehensive income tax (global tax) dalam penghitungan penghasilan dari modal. ${ }^{20}$ Ada kecenderungan beralih ke dual income tax. ${ }^{21}$

Pemisahan tambah tegas dari tarif umum atas penanganan penghasilan modal dari dividen $10 \%$ dari bruto untuk WP OP dalam negeri. ${ }^{22}$

2. Terbit kewajiban/ketentuan potong $\mathrm{PPh}$ berpasal 23 bersifat, final dan bertarif $15 \%$ dari nilai bruto terhadap bunga simpanan koperasi yang dibayarkan.

Pajak pasal 23 ini dikenakan baik pada WP OP maupun WP Badan, berlaku dan dijalankan sampai dengan UU PPh No. 36/2018, dimana di UU ini pajak tersebut diubah, menjadi objek $\mathrm{PPh}$ final Pasal 4 ayat (2) untuk WP OP dan objek PPh Pasal 23 untuk WP Badan yang bersifat tidak final.

3. Aturan pada pasal 15 diubah, terkait dengan penerapan norma penghitungan yang dikhususkan bagi suatu hasil neto/bersih dari WP Tertentu yang tak bisa dikalkulasi menurut aturan UU PPh berpasal 16 (angka 1 atau 3).

Penerapan pasal ini dituangkan dalam KMK (menteri keuangan yang memutuskan) yang bernomor 632/KMK.04/1994 (KMK 632/1994), tarif $\mathrm{PPh}$ finalnya sebesar $2,64 \%$ atas peredaran bruto berupa pemberian/imbalan dari perusahaan pelayaran atau penerbangan dari pengangkutan orang dan/atau barang yang diangkut dari atau mengarah satu atau lebih pelabuhan di Indonesia ke luar negeri atau sebaliknya bagi WP LN.

Selanjutnya KMK 632/1994 digantikan dengan KMK No. 181/KMK.04/1995(KMK 181/1995) perihal norma yang dikhususkan penghitungannya dari hasil neto/bersih bagi WP

${ }^{19}$ Peter Birch Sorensen. "Dual Income Taxes: A Nordic Tax Syste”. Dalam Iris Claus et.al. (eds). Tax Reform in Open Economies, (Edward Elgar, 2010).

${ }^{20}$ Richard M. Bird dan Eric M. Zolt. "Dual Income Taxation and Developing Countries". Columbia Journal of Tax Law. Vol. 12010 , h. 174-217.

${ }^{21}$ Peter Birch Sorensen. "The Nordic Dual Income Tax: Principles, Practices, and Relevance for Canada". Canadian Tax Journal. Vol. 55 No. 3 2007, h. 557-602.

22 Pasal 17 ayat (2c) UU PPh Tahun 2008 dan diperjelas melalui PP No. 19 Tahun 2009. berusaha di sektor pelayaran atau penerbangan, KMK 181/1995 ini mengatur bahwa baik WP DN maupun WP LN sama-sama dikenakan pajak atas imbalan yang diterima atau diperoleh perusahaan pelayaran atau penerbangan dari pengangkutan orang dan/atau barang yang dimuat dari atau menuju satu atau lebih pelabuhan di Indonesia ke luar negeri atau sebaliknya, WP LN diterapkan tarif 2,64\% final, sedang WP DN diterapkan tarif $1,8 \%$ tidak final sifatnya.

Selang satu tahun, KMK 181/1995 dicabut dan dibuatkan tiga aturan pengganti yakni: a. KMK bernomor 416/KMK.04/199 perihal norma dikhususkan penghitungannya dari hasil neto/bersih bagi WP yang berusaha berusaha di sektor pelayaran dalam negeri, tarifnya $1,2 \%$ dari peredaran bruto, berkriteria final; b. KMK bernomor 417/KMK.04/1996 (KMK 417/1996) perihal norma yang dikhususkan penghitungannya dari hasil neto/bersih bagi WP yang berusaha di sektor pelayaran dan/atau penerbangan luar negeri, tarifnya $2,64 \%$ dari peredaran bruto, bersifat final; c. KMK bernomor 475/KMK.04/1996 (KMK 475/1996) perihal norma yang dikhususkan penghitungannya dari hasil neto/bersih bagi WP yang berusaha di sektor penerbangan Dalam Negeri, dengan tarif $1,84 \%$, kriteria tidak final.

4. Ada perluasan PPh Pasal 26, melalui penambahan jenis objek penghasilan baru.

Obyek PPh pasal 26 meliputi hadiah yang diberikan dan penghargaan, pensiun dan pembayaran bertahap lainnya, penghasilan dari pelepasan harta di Indonesia dan premi pengasuransian yang dibayarkan kepada perusahaan sektor asuransi di luar negeri, diatur dalam KMK No. 624/KMK.04/1994 (KMK 624/1994). Pada reformasi ini juga diberi aturan pelaksana terhadap branch profit tax (KMK No. 602/KMK.04/1994.

5. PPh final Pasal 19 atas revaluasi aset.

Tata caranya diatur dalam KMK No. 507/ PMK.04/1996 (KMK 507/1996) yang intinya ada pengenaan $\mathrm{PPh}$ final 10\% atas selisih lebih dari revaluasi aset setelah dikompenasi kerugian, dan KMK ini mengalami pembaruan beruntun dari KMK 507/1996, kemudian KMK 18/1998, dan terakhir KMK 384/1998. 
6. PPh Pasal 21 yang berkriteria final atas honorarium yang didapat para pejabat negara, PNS, TNI, dan Polri yang dananya dibebankan pada APBN/APBD, dasarnya PPh Pasal 21 ayat (5).

Pasal ini teknisnya dapat dilihat di PP No. 45 Tahun 1994(PP 45/1994), dimana ada PPh final $15 \%$ yang dipotong dari jumlah bruto.

7. Ada pengenaan PPh berkriteria final berpasal 22 terhadap penjualan jenis produk tertentu yang diatur dalam keputusan menteri keuangan.

Diatur di KMK No. 599/KMK.04/1994(KMK 599/1994), aturannya bahwa hasil produksi BBM berjenis premix dan gas, yang dijual Pertamina dan badan usaha selain Pertamina pada para penyalur dan/atau agennya dipungut $\mathrm{PPh}$ berpasal 22 yang berkriteria final.

\section{d. Reformasi UU PPh Tahun 1997}

Sebenarnya reformasi pajak 1997 satu paket dan tujuan dengan reformasi pajak 1994, tertunda masuk tahun 1997. Politik hukum reformasi perpajakan 1983 serta 1994 banyak tercapai, yakni berperan dalam peningkatan penerimaan pajak sebesar $70 \%$ ke atas, dimana PPh dan PPN menjadi penopang utamanya. Lanjutan reformasi pajak yang terjadi di tahun 1997, terbitlah pengesahan 5 buah undangundang yang juga mengandung politik hukum untuk mengamankan sumber penerimaan pajak baik di pusat dan daerah, dan motivasinya tetap berupa peningkatan pelayanan kepada WP secara menyeluruh, dapat diuraikan sebagai berikut:

a. UU bernomor 17 bertahun 1997 perihal BPSP merupakan lembaga penyelesaian sengketa pajak. Pembentukan BPSP dimaksudkan untuk menghadirkan keputusan dan kepastian hukum dengan segera pada saat ada sengketa pajak (banding)

b. UU bernomor 18 bertahun 1997 mengenai PDRD yang atur perpajakan dan perestribusian daerah. Politik hukum dari penertiban pungutan pajak daerah supaya jelas bagi investor, menghadirkan rasa keadilan, aman dan nyaman masyarakat.

c. UU bernomor 19 bertahun 1997 mengenai PPSP (Penagihan Pajak Dengan Surat Paksa). UU bernomor 19 bertahun 1997 ini wujud aturan yang melengkapi UU bernomor 9 bertahun 1994. d. UU bernomor 20 bertahun 1997 perihal PNBP yang atur pendapatan yang diterima negara bukan berbentuk pajak.

e. UU bernomor 21 bertahun 1997 mengenai BPHTB. Penghitungan BPHTB dasarnya pakai NJOP dalam PBB atau nilai pasar mana yang lebih tinggi setelah dikurangi NJOP TKP lalu dikalikan tarif 5\%.

\section{e. Reformasi UU PPh Tahun 2000}

Fokus pada PPh final Pasal 4 angka 2, perubahan ketiga UU PPh tidak signifikan memberi dampak, tapi memberi geliat pembaruan yang terus berlangsung. Terbit Peraturan Pemerintah bernomor 149 bertahun 2000, PPh final yang ditambahkan dan berlaku yaitu pengenaan PPh final 21 atas uang tebusan pensiun, uang THT atau JHT, uang pesangon yang diterima pegawai atau mantan pegawai. Lalu objek PPh final Pasal 26 atas penghasilan premi swap, ditambahkan dengan tarif $20 \%$ (dua puluh persen).

\section{f. Reformasi UU PPh Tahun 2008}

Pengenaan $\mathrm{PPh}$ final mengalami perubahan signifikan pada amandemen keempat UU PPh, ada lima poin perubahan yakni:

1. Perubahan isi PPh berpasal 4 (angka 2), yang sekaligus memperluas jenis penghasilan yang dapat dikenakan pajak final.

Penghasilan final ini meliputi dari: Pertama, hasil bunganya deposito dan simpanan lainnya, hasil bunganya obligasi dan surat utang negara (SUN), dan hasil bunganya simpanan yang diberikan koperasi kepada anggotanya; Kedua, hasil hadiah dari undian; Ketiga, perdagangan saham/efek dan sekuritas lainnya, transaksi derivatif yang ditransaksikan di paar saham/ efek, dan transaksi pelepasan saham atau pemindahan penyertaan modal pada perusahaan pasangannya yang didapat oleh perusahaan modal patungan; Keempat, pelepasan tanah dan/ atau yang dibangun di atasnya, jasa di bidang perkonstruksian, real estate, dan persewaan bumi dan/atau sesuatu yang dibangun di atasnya; dan Kelima, pendapatan dikhususkan lainnya, yang penerapan/pelaksanaan melalui PP.

Ragam obyek $\mathrm{PPh}$ final selain sudah ada sebelumnya ditambah ragam lain. Penghasilan tidak saja dari penghasilan modal (capital 
income) tapi dari kegiatan bisnis semisal usaha jasa konstruksi, serta penghasilan lainnya (other income) seperti hadiah undian.

2. Perubahan obyek yang semula $\mathrm{PPh}$ pasal 23 (final) jadi obyek PPh pasal (4 angka 2) final atas hasil bunganya simpanan yang pemberiannya oleh koperasi terhadap anggotanya.

3. $\mathrm{PPh}$ Pasal 26, terdapat perluasan objek pajak dengan menambah jenis penghasilan yang dapat dikenai PPh final, yakni keuntungan disebabkan hutang yang dibebaskan dan pelepasan saham di wilayah NKRI (PMK bernomor 258/ PMK.03/2008).

4. Pada perombakan UU PPh terakhir ini, ada aturan baru yaitu pasal 17 ayat (2) huruf c perihal $\mathrm{PPh}$ dividen ada tarif final $10 \%$ dari bruto untuk WP OP (lihat di PP No. 19 Tahun 2009).

5. Penerbitan PP bernomor 46 bertahun 2013 (PP 46/2013), PP ini mengenai pemajakan final atas pengusaha berkriteria mikro kecil dan menengah dengan bertarif $1 \%$ dari peredaran bruto, tidak melebihi dari nilai 4,8 milyar, lalu dicabut dan diganti dengan PP bernomor 23 bertahun 2018 (PP 23/2018 dengan bertarifkan 0,5\%.

Sedang aturan-aturan $\mathrm{PPh}$ final lainnya sama dengan aturan sebelumnya.

\section{Reformasi Birokrasi}

\section{a. Reformasi Perpajakan Tahun Pertama}

Tahun 2002 sampai dengan 2008, muncul bentuk One Stop Services sebagai wujud pembaruan organisasi perpajakan di DJP, diisi dengan keberadaan 2 (dua) Kantor Pajak WP Besar, 10 (sepuluh) Kantor Pajak Khusus, 32 (tiga puluh dua) Kantor Pajak Madya, dan 357 (tiga ratus lima puluh tujuh) Kantor Pajak Pratama di wilayah NKRI.

\section{b. Reformasi Perpajakan Tahap Kedua}

Reformasi ini terjadi pada rentang waktu tahun 2009 sampai dengan 2014, berfokus peningkatan internal kontrol DJP dan meningkatkan pelayanan secara keseluruhan. Reformasi terhadap proses bisnis dan IT. Pembentukan panduan Standar Operating Procedure (SOP) untuk pelayanan perpajakan, biasa disebut 16 (enam belas) layanan unggulan DJP, termasuk pembuatan NPWP 1 hari kerja.

\section{c. Reformasi Perpajakan Jilid Ketiga}

Reformasi ini berjalan dari tahun 2017 dan ada rencana pencapaian-pencapaian hingga 2024, merupakan reformasi terbesar karena mencakup lima penyangga utama, yakni Organisasi, SDM, IT dan Basis Data, Proses Bisnis, dan Peraturan Perpajakan. Pilar Organisasi, SDM, dan Peraturan diharap selesai tahun 2020. Pilar lain, berupa IT dan Basis Data serta Proses Bisnis, dilakukan pembenahan berkelanjutan.

Reformasi jilid III ini diawali dengan permulaan yang bagus yaitu dengan selesainya program Tax Amnesty, didukung dengan program Automatic Exchange of Information (AEoI). Pemerintah berpentingan meningkatkan rasio pajak dan kepatuhan wajib pajak ujungnya penerimaan pajak jadi optimal.

Bagian reformasi perpajakan jilid III belum selesai, pastinya, sudah dicanangkan road mapnya pada Nota Keuangan beserta RAPBN Tahun Anggaran 2021, seperti diuraikan di bawah ini: ${ }^{23}$

\section{Reformasi Perpajakan Tahun 2021 sampai dengan Tahun 2024}

Pemerintah saat ini sedang berusaha untuk menstimulasi dunia usaha untuk pulih di tengah pandemi Covid-19 dengan tetap berfokus mencapai Visi Indonesia 2045. Tujuan reformasi pajak kali ini, memprioritaskan hal-hal sebagai berikut:

a. Stimulasi kemajuan ekonomi dengan program pemulihan yang bersinergi, antara lain: a. Insentif perpajakan untuk PPh final dan PPh Pasal 21 serta pengurangan angsuran $\mathrm{PPh}$ Pasal 25; $\mathrm{b}$. Tarif PPh WP Badan diturunkan, sedang dalam aktivitas impor usaha tertentu ada pembebasan $\mathrm{PPh}$ impor dan bea masuk.

b. Optimalisasi penerimaan negara, melalui: a. Perbanyak objek pajak baru diharap berimbas positif pada rasio perpajakan, misal pemajakan transaksi online (PMSE); b. Perbaikan tata kelola dan administrasi perpajakan.

\section{PENUTUP}

\section{Kesimpulan}

Simplifikasi pajak harus diterapkan berdasarkan sudut pandang yang luas dalam menerapkan konsep-konsep pajak pada umumnya. Penekanan dari simplifikasi ini adalah sarana menggapai maksud simplifikasi tersebut, yang meliputi akurasi perencanaan pajak, keterbukaan, setara, efisiensi,

${ }^{23}$ Nota Keuangan beserta RAPBN Tahun Anggaran 2021. Bab 2 Pendapatan Negara, h. 2-8. 
mudah dimengerti dan dapat meminimalisir peluang terjadinya penghindaran pajak (tax evasion) .

Pembentukan UU PPh tahun 1983 menjadi permulaan munculnya aturan final yang kemudian bergulir terus dalam tahapan reformasi pajak selanjutnya, diantaranya $\mathrm{PPh}$ Pasal 4, 15, 17, 19, 21, 22 dan 26. Penerapan PPh final juga mengindikasikan adanya perpindahan sistem perpajakan dari global ke schedule tax system berbasis pemilahan ragam penghasilan dari modal maupun pekerjaan, serta berpatokan pada keluarga dengan ketentuan presumptive tax sebagai bentuk simplikasi. Pengklasifikasian jenis PPh final sesuai karakter meliputi PPh final atas, (a) penghasilan SPLN, (b) penghasilan dari modal (disendirikan dari penghasilan pekerjaan), (c) kepentingan untuk menerapkan kebijakan presumptive tax, (d) pemajakan berbasis keluarga, serta (e) kepentingan simplifikasi, kepatuhan, dan penerimaan.

\section{Rekomendasi}

Penerapan metode simplifikasi pajak harus senantiasa dikembangkan agar tepat guna, melalui kebijakan, aturan dan prosedur, administrasi pajak serta tata cara komunikasi antara wajib pajak dan fiskus. Politik hukum reformasi hukum pajak dalam simplifikasi dan penerapan $\mathrm{PPh}$ final hendaknya berkaitan dan mengarah kepada peningkatan kepatuhan agar dapat diantisipasi terjadinya pemanfaatan aturan pajak oleh wajib pajak, antisipasi celah kesenjangan terhadap kontiunitas pemasukan pemerintah, pemberian kemudahan bagi wajib pajak secara proporsional dan merata, peningkatan daya saing terhadap penghasilan yang bersifat modal, inventarisasi basis data wajib pajak yang konsisten dan didukung oleh modernisasi administrasi, kemudahan penerapan aturan hukum pajak terutama $\mathrm{PPh}$ final melalui aturan teknis pada hierarki di bawah Undang-Undang.

\section{DAFTAR PUSTAKA}

\section{Peraturan Perundangan-undangan:}

Undang-Undang Dasar Negara Republik Indonesia Tahun 1945.

Undang-Undang Nomor 7 Tahun 1983 tentang Pajak Penghasilan.
Undang-Undang Nomor 20 Tahun 2000 tentang Bea Perolehan Hak Atas Tanah dan Bangunan (BPHTB).

Undang-Undang Nomor 36 Tahun 2008 tentang Pajak Penghasilan.

Undang-Undang Nomor 16 Tahun 2009 tentang KUP (Ketentuan Umum dan Tata Cara Perpajakan).

Undang-Undang Nomor 42 Tahun 2009 tentang Pajak Pertambahan Nilai (PPN) dan/atau Penjualan Barang Mewah (PPnBM).

Undang-Undang Nomor 11 Tahun 2016 tentang Pengampunan Pajak.

Peraturan Pemerintah No. 42 Tahun 1994 tentang Pajak Penghasilan Atas Hadiah Undian.

Peraturan Pemerintah No. 19 Tahun 2009 tentang Pajak Penghasilan Atas Dividen Yang Diterima atau Diperoleh Wajib Pajak Orang Pribadi Dalam Negeri.

\section{Buku:}

Carl Joachim Friedrich. (2004). Filsafat Hukum Perspektif Historis. Bandung: Nuansa dan Nusamedia.

Darussalam, et.al. (2019). Era Baru Hubungan Otoritas Pajak dengan Wajib Pajak. Jakarta: PT. Dimensi Internasional Tax.

Hyronimus Rhiti. (2015). Filsafat Hukum Edisi Lengkap (Dari Klasik ke Postmodernisme). Cetakan Kelima. Yogyakarta: Universitas Atma Jaya.

Mahfud. (2010). Politik Hukum, Jakarta: PT. Raja Grafindo Persada.

Mardiasmo, (2016). Perpajakan Edisi Revisi. Yogyakarta: Andi Offset.

Sylvan R.F. Plasschaert. (1988). Schedular, Global and Dualistic Patterns of Income Taxation. Amsterdam: IBFD.

\section{Jurnal dan Artikel:}

B. Bawono Kristiaji dan Awwaliatul Mukarromah. Meninjau Konsep dan Relevansi PPh Final di Indonesia. DDTC Working Paper 2220, tgl. 04 Mei 2020.

Christian Vossler dan Michael McKee. "Behavioral Effects of Tax Withholding on Tax Compliance: Implications for Information Initiatives". Department of Economics Working Paper, No. 15-12 (2015): 1. 
Cinantya Kumaratih dan Budi Ispriyarso, "Pengaruh Kebijakan Perubahan Tarif PPH Final Terhadap Kepatuhan Wajib Pajak Pelaku UMKM," Jurnal Pembangunan Hukum Indonesia, vol. 2, no. 2, pp. 158-173, May. 2020. https://doi. org/10.14710/jphi.v2i2.158-173

Deden Sumantry, (2011), "Reformasi Pajak untuk Perlindungan Hukum di antara Wajib Pajak dengan Fiskus Sebagai Pelaksanaan Terhadap UU Perpajakan", Jurnal Legislasi Indonesia, vol. 8 no. 1, h. 13-28, April 2011

Hillary S.P. Ratuela, Jullie J. Sondakh, Anneke Wangkar, 2018,"Analisis Penerapan Pajak Penghasilan Final Pasal 4 ayat (2) Atas Jasa Konstruksi Pada PT. Realita Timur Perkasa", Jurnal Riset Akuntansi Going Concern ,13(4), 2018, 856-866

Lee Burns dan Richard Krever, "Individual Income Tax," dalam Tax Law Design and Drafting, Volume 2, ed. Victor Thuronyi (United Kingdom: IMF, 1998), h. 495.
Michael Carnahan. "Taxation Challenges in Developing Countries". Asia \& Pacific Policy Studies, Vol. 2 No. 1 (2015): 176.

Nota Keuangan beserta RAPBN Tahun Anggaran 2021. Bab 2 Pendapatan Negara.

Peter Birch Sorensen. "Dual Income Taxes: A Nordic Tax System". dalam Iris Claus et.al. (eds). Tax Reform in Open Economies, (Edward Elgar, 2010).

Peter Birch Sorensen. "The Nordic Dual Income Tax: Principles, Practices, and Relevance for Canada”. Canadian Tax Journal, Vol. 55 No. 3, 2007, h. 557-602.

Richard M. Bird dan Eric M. Zolt. "Dual Income Taxation and Developing Countries". Columbia Journal of Tax Law, Vol. 1 (2010): 201.

Richard M. Bird dan Eric M. Zolt. "Dual Income Taxation and Developing Countries". Columbia Journal of Tax Law Vol. 1, 2010, h. 174-217. 